\title{
The regulative function of mentalization and mindfulness in borderline personality organization
}

\author{
Monika Marszat ${ }^{1 \cdot A, B, C, D, E, F, G}$, Dominika Górska ${ }^{2 \cdot A, B, C, D, E, F}$ \\ 1: Institute of Psychology, University of Social Sciences and Humanities, Poznan, Poland \\ 2: Institute of Psychology, Adam Mickiewicz University in Poznan, Poznan, Poland
}

\section{BACKGROUND}

The aim of this study was to broaden the understanding of the emotional difficulties of borderline personality organization (BPO) by reference to a meta-ability named 'orientation on the internal world', here conceptualized as mentalization and mindfulness, in the framework of object relation theory. It was assumed that it is not mentalization "in itself", but mainly its regulatory function, that is important for BPO.

\section{PARTICIPANTS AND PROCEDURE}

The clinical and control groups (30 individuals each) were examined using The Mental States Task, The Difficulties of Emotion Regulation Scale and The Mindful Attention Awareness Scale.

\section{RESULTS}

Individuals with BPO functioned worse than the control group in terms of mentalization, mindfulness, and emo- tion regulation. The relationship between $\mathrm{BPO}$ and the meta-abilities was mediated by emotional dysregulation: total mediation was revealed for one mentalization dimension, and partial mediation was observed for mindfulness.

\section{CONCLUSIONS}

Orientation on emotional experience and emotional dysregulation are not independent predictors of BPO, but they can be treated as levels in the hierarchical model. Mentalization determines and influences emotion regulation in BPO.

\section{KEY WORDS}

mentalization; mindfulness; emotional dysregulation; borderline personality organization

CORResPonding AUthor - Monika Marszał, Ph.D., Institute of Psychology, University of Social Sciences and Humanities, 10 Gen. Tadeusza Kutrzeby Str., 61-719 Poznan, Poland, e-mail: mmarszal@amu.edu.pl AUthors' Contribution - A: Study design · B: Data collection · C: Statistical analysis · D: Data interpretation · E: Manuscript preparation · F: Literature search · G: Funds collection

TO CITE THIS ARTICLE - Marszał, M., \& Górska, D. (2015). The regulative function of mentalization and mindfulness in borderline personality organization. Current Issues in Personality Psychology, 3(1), 51-63. RECEIVED 09.12.2014 · REVIEWED 02.02.2015 · ACCEPTED 16.03.2015 · PUBLISHED 27.03.2015 


\section{BACKGROUND}

Severe dysfunctions in emotional functioning are among the key characteristics of borderline personality pathology. These are conceptualized as emotional dysregulation (Linehan, Bohus, \& Lynch, 2007; Linehan, 1993) and include, among others, impulsivity, poor negative affect tolerance, excessive levels of constitutional aggression, and difficulty in coping with this in an adaptive manner (Kernberg, 2004). The research indicates the high intensity of experienced emotions and the lack of ability to reduce the arousal in an efficient manner (Andersen, Timmerby, \& Simonsen, 2012; Linehan, 1993). Moreover, it has been shown that borderline individuals are characterized by low levels of emotional awareness and by problems with recognizing emotions (Beblo et al., 2010); they are also more likely to experience negative emotions such as anger, anxiety, and depression (Ebner-Priemer et al., 2007; Sarkar \& Adshead, 2006). Borderline pathology is also associated with alexithymia (Guttman \& Laporte, 2002).

Apart from this, severe personality pathology (mainly of borderline type) is also described by impairments in abilities generally characterized as orientation towards subjective experiences, creating mental space, interpreting one's behavior in terms of mental states, and monitoring the inner experience. These types of abilities are involved in concepts such as mentalization (Fonagy \& Luyten, 2009; Fonagy et al., 2013), mindfulness (Kabat-Zinn, 1990), metacognition (Dimaggio et al., 2008), psychological mindedness (Hall, 1992), mind-mindedness (Meins, Fernyhough, Fradley, \& Tuckey, 2001), and verbal elaboration of affect (Lecours, 1995). These constructs have their roots in psychoanalytic theory (see also the symbolic equation; Klein, 1996; Bion, 1962). More recently, the tempo of research on two such constructs has increased: mentalization in the psychodynamic approach (Fonagy \& Luyten, 2009) and mindfulness in the cognitive-behavioral approach (Leahy, Tirch, \& Napolitano, 2011).

Severe difficulties in emotion regulation and impairments in reflective orientation on one's own mental states are considered to be mechanisms underlying borderline personality. An extended understanding of the interactions between these two processes is offered by developmental models referring to personality structure. One of these models is the object relations theory of Otto F. Kernberg (1967, 2004), which indicates that the root of the impairments in emotional regulation lies in nonintegrated, split intrapsychic structures and in the inability to orientate oneself in internal emotional states, coexisting with splitting. Within this theory, the concepts of mentalization and mindfulness can be useful for explaining borderline pathology, defined as the level of personality organization (borderline personality organization - BPO, see Kernberg, 2011). Personality organization refers to Kernberg's structural model of personality, which indicates the increasing severity of personality pathology (Caligor \& Clarkin, 2013). There are three levels of personality organization normal, neurotic, and borderline - depending on the developmental level of the intrapsychic structures, such as identity integration, the quality of object relations, reality testing, the maturity of defense mechanisms and moral functioning.

In the present study, we concentrate on borderline personality organization, which includes severe personality disorders (such as borderline personality disorder, as well as narcissistic, paranoid, and antisocial personality disorders) (Kernberg, 2004). Borderline personality organization differs from the higher personality organizations in terms of the major disturbances in emotional functioning that are the result of substantial impairments in the internal representation caused by developmental abnormalities. In particular, the internal representations are split, and partial representations that contain intense paranoid and aggressive affects cannot be integrated with libidinal representations, and so cannot be neutralized. In the inner world, the negative self-object representations predominate, and the good objects are deficient, being impossible to recall during emotional arousal. In Kernberg's theory, the relationship between the internal representations (their level of integration) and the impairments in emotion regulation are also emphasized (Kernberg, 2011). Both mentalization and mindfulness may develop through a process of ongoing integration of the representations; the two processes are therefore considered to be impaired in BPO.

On the basis of Kernberg's theory, when responding to a question about the meaning of mentalization and mindfulness in borderline personality organization, we focus on a model that assumes a specific relationship between the orientation towards subjective experience and emotion regulation. We hypothesize that, in explaining borderline personality pathology, what is important is not the ability to reflect upon mental states and to take the "observer" perspective to the subjective experience itself, but the impact of this process on the ability to regulate emotions. We therefore place emphasis on the regulatory role of these metafunctions in particular. Moreover, both of these concepts are considered in the individual perspective; that is, we refer only to the orientation towards the mental states of the self, and not others.

\section{MENTALIZATION AND MINDFULNESS FROM THE EMPIRICAL PERSPECTIVE}

It has been well established that mentalization and mindfulness are to some extent similar, but that there are certain points at which they considerably differ 
from each other (Choi-Kain \& Gunderson, 2010). Mentalization is defined as preconscious mental activity that perceives and interprets behavior in terms of intentional mental states, such as desires, feelings, beliefs, needs, and intentions (Fonagy et al., 2013). It is based on the ability to form a system of representation and to differentiate between subjective mental experience and the external world. In the literature, it is indicated that mentalization is a multidimensional construct, which implies functioning in two modes (automatic and controlled), concerns two objects (self and others), and is manifested in two aspects (cognitive and affective). Mentalization is considered as an essential process for adequate navigation of the social world. The authors emphasize, however, that in addition to its importance for interpersonal functioning, its self-regulating function, associated with the ability to regulate emotions and maintain a stable sense of self, is crucial (ibid). Moreover, mentalization in Fonagy's perspective is considered in the context of attachment theory, in terms of both the developmental and interpersonal aspect. The evidence suggests a relationship between secure attachment and the acquisition of the ability to mentalize in the early years of life (Meins et al., 2001). It also shows that mentalization changes in different contexts - these being understood as the activation of specific internal working models of attachment. It is assumed that the level of mentalization is not a constant trait of the person, but may vary depending on the relationship that mentalization reveals (Bateman \& Fonagy, 2013; Fonagy et al., 2013).

Mindfulness, in turn, has its roots in the traditions of the Far East, including in Buddhism and meditation techniques (Shapiro, Carlson, Astin, \& Freedman, 2006). According to the most established definition, that of Kabat-Zinn (1990), mindfulness is a special kind of awareness: a conscious, purposeful, nonjudgmental awareness that is aimed at experience and lasts from moment to moment, in the here and now. Jankowski (2006) describes mindfulness as inhibiting several cognitive processes, such as interpretation, evaluation, analysis, and comparison of experiences. Bishop et al. (2004) considers mindfulness to be a type of self-regulation of the attention that focuses on the direct experience, which allows an increased recognition of one's own mental states in the present moment. In each of these definitions, two basic elements of the process can be distinguished: self-regulation of the attentional processes (the recognition of mental states at a present moment) and an open, accepting attitude toward the experience (Choi-Kain \& Gunderson, 2008). The core mechanism of mindfulness is considered to be the shift in perspective named reperceiving, which involves a distancing from the experience, the capacity to take an "observer's" perspective to one's own mental states (Shapiro et al., 2006), and a metaperspective instead of immersion in the emotional experience. A change of perspective supports regulatory processes; additional data gained due to reperception reduce the tendency to use habitual strategies of emotion dysregulation, such as emotional avoidance (Hayes, Strosahl, \& Wilson, 1999). It also increases emotional flexibility and the ability to experience intense emotions with greater objectivity and less reactivity. From the developmental perspective, mindfulness is associated with cognitive development, mainly attentional processes; its relationship to attachment security has also been demonstrated (Walsh, Balint, Smolira, Fredricksen, \& Madsen, 2009; Saavedra, Chapman, \& Rogge, 2010).

Researchers have pointed to the similarities between mindfulness and mentalization: both processes refer to experiencing, observing, and reflecting on mental states (Choi-Kain \& Gunderson, 2008). Yet there are also substantial differences between them. Mindfulness assumes a conscious, careful acting with awareness and an attitude of accepting without judgment; these aspects are not present in mentalization. Moreover, the concept of mindfulness relates merely to one's own mental states directly, whereas mentalization implies the ability to reason about the mental states of the other. It is also said that mindfulness is associated with more conscious monitoring and controlling of mental processes, although this is not always manifested in verbal form. It does not concern the unconscious, automatic aspect of the mental processes, but refers only to its explicit form (Choi-Kain \& Gunderson, 2008). The two constructs also differ in terms of their temporal perspective: mindfulness applies only to the present, while the ability to mentalize properly also implies a reference to the past and the future. Other significant differences concern the aims of the two processes: in mentalization, the most important outcome is to create an adequate representation of the mind (one's own or others), whereas in mindfulness, it is crucial to maintain the overall acceptance of one's own mental states. Importantly, mentalization involves emotional arousal, understood as the activation of internal representations of attachment relationships. According Choi-Kain and Gunderson (2008), mentalization and mindfulness appeal to the emotional and cognitive processes equally, although mindfulness is defined by many authors as the only cognitive ability that relates solely to the cognitive content. It may be useful to distinguish between the nature of the process and the content that is the subject of the mentalizing or mindfulness. The content of mindfulness, as in mentalization, can as easily be emotional as cognitive, that is, it concerns both emotions and beliefs or intentions. In contrast, the process itself in mindfulness is more cognitively oriented than in mentalization, where the emotional aspect of understanding and reflecting mental states is emphasized. This cannot be observed in mindfulness. 
A broader understanding of mentalization and mindfulness in the context of Kernberg's theory refers to the development of intrapsychic structures. Accurate mentalization and mindfulness can only occur when the internal representations are integrated and mature. To be mindful means to focus on the feelings that arise without reacting to them, and without taking action as a result of them. Kernberg (2011) compares mindfulness to Bion's concept of container-contained, a dynamic mechanism described in psychoanalysis as processing feelings by the good object (cf. Bion, 1962; Groth, 2005), in contrast to externalizing feelings in the form of acting out. He also emphasizes the entirely conscious aspect of this process. On the other hand, mentalization is described by Kernberg as the key mechanism of emotion regulation, which is possible only when there is an integrated self, forming the framework for "emerging" from emotions. This process is impossible in the case of borderline pathology, where the splitting coexists with extremely intense, overwhelming emotional experience.

\section{ORIENTATION TO SUBJECTIVE EXPERIENCE AND EMOTION DYSREGULATION IN A BORDERLINE PERSONALITY ORGANIZATION}

The foregoing considerations show that mindfulness and mentalization are defined as states of mind oriented on subjective experience, and that the ability to perceive, recognize, and reflect on this experience can be conceptualized as the functions responsible for emotion regulation. Thus, they are a specific kind of metafunction that controls emotion regulation strategies and their outcomes, and it is in terms of their impairments that emotional symptoms can be observed. In the cognitive-behavioral approach, mindfulness has primacy over emotion regulation (Leahy et al., 2011), while in the psychodynamic approach, mentalization is considered to determine the transformation of the primitive affect representations in secondary representations (Kernberg, 2011), which enables a major increase in the level of emotion regulation. As noted earlier, both emotion regulation and orientation to subjective experience are considered to be predictors of personality pathology.

Mentalization and borderline personality organization. The research into the relationships between mentalization and BPO reveals the very complex nature of the ability to mentalize, both in terms of its multidimensionality and of the interplay between mentalization deficits and the activation of certain psychic structures. It has been shown that mentalization should be considered a state rather than a feature - it is dependent on the context, that is, on the attachment representation which is being activated in the moment (self-object-affect dyads) (O'Connor \& Hirsch, 1999; Kernberg, Diamond, Yeomans, Clarkin, \& Levy, 2008; Vermote et al., 2009; Marszał, 2015). Not all studies reveal relationships between mentalization and BPO, and some consider only a few of its aspects. For example, Sharp et al. (2011) found significant results only for hypermentalizing, but not for mentalizing or undermentalizing. Research using the Reading the Mind in the Eyes Test (Baron-Cohen, Wheelwright, Hill, Raste, \& Plumb, 2001), considered a perceptual aspect of the theory of mind, even suggests the better functioning of borderline individuals than the control group (Fertuck et al., 2009; Scott, Levy, Adams, \& Stevenson, 2011). An inverse relationship is observed in studies involving more complex tasks which capture many aspects of mentalization and assume emotional arousal during measurement (activation of the attachment system). Borderline individuals have difficulty mentalizing when measured by the Adult Attachment Interview (i.e., reflective function; Fonagy, 1999; Fisher-Kern et al., 2010), as well as by the Verbal Elaboration of Affect (GEVA) (Lecours, 1995) and the Measure of Affect Content (MAC) (Lecours \& Bouchard, 2011) instruments. The evidence suggests a relationship between a high level of mentalization and defense mechanism maturity, which indicates personality organization higher than borderline (Górska, 2013). Researchers have indicated the relationship between mentalization and emotion regulation, including in its developmental aspect (Fonagy \& Luyten, 2009; Sharp et al., 2011). Mentalization includes some aspects of emotion regulation itself, such as the ability to identify and elaborate emotional states, as well as effective coping with negative affect (Semerari, Carcione, Dimaggio, Nicolò, \& Procacci, 2007). Moreover, research shows a relationship between the impairments in mentalization and alexithymia (Moriguchi et al., 2006).

Mindfulness and borderline personality organization. In borderline patients, the inability to cope with intense negative affect coexists with a tendency to avoid internal and external stimuli that might cause distress (Wupperman, Fickling, Klemanski, Berking, \& Whitman, 2013). However, from the developmental perspective, the experience of a threatening and unstable caregiver leads to the invalidation and denial of the subjective experience, which may be the cause of learned unawareness of one's own mental activity and the tendency to avoid an orientation towards mental states (Wupperman, Neumann, Whitman, \& Axelrod, 2009). These results indicate a correlation between the borderline traits and low levels of mindfulness, both in the clinical group (Baer, Smith, \& Allen, 2004; Wupperman, Neumann, \& Axelrod, 2008; Fossati, Vigorelli Porro, Maffei, \& Borroni, 2012) and in the nonclinical population (Wupperman et al., 2008). It has also been shown that a low level of mindfulness is characteristic for other personality 
disorders (Saulsman \& Page, 2004). There is a relationship between low levels of mindfulness and the personality disorders associated with low levels of structural personality organization: antisocial, schizoid, avoidant, paranoid, narcissistic, borderline, and schizotypal (Fossati et al., 2012). Wupperman et al. (2013) indicated the mediating role of mindfulness in the occurrence of BPD and of behaviors indicating maladaptive methods of coping, such as self-harm, substance abuse, and aggressive behavior. A relation between low levels of emotional intelligence, on one hand, and borderline symptoms, emotional dysregulation, and a low level of mindfulness, on the other, has also been demonstrated (Sinclair \& Feigenbaum, 2012).

Mindfulness reveals a strong relationship with affective functioning and emotion regulation. Low awareness of mental states reduces the ability to tolerate and regulate the negative affect and increases the tendency to avoid emotional experience (Wupperman et al., 2008; Linehan, 1993). Mindfulness is associated with affect consciousness, psychological mindedness, and a low level of alexithymia (Bishop, et al., 2004). A high level of mindfulness influences the appreciation and understanding of emotional states, and creates an opportunity to cope with negative emotions (Brown \& Ryan, 2003; Fossati et al., 2012). A low level of mindfulness, on the other hand, reinforces emotional impairments, such as high levels of depression and anxiety (Hofmann, Sawyer, Witt, $\& \mathrm{Oh}, 2010)$, and is connected with a high rate of negative affect and a low incidence of positive emotions (Carlson \& Brown, 2005; Fossati et al., 2012). Brown and Ryan (2003) have shown that mindfulness is associated with some aspects of emotion regulation, such as the ability to maintain positive affect, to draw attention to emotional sensations, to reduce distress, and clarity of emotional experiences. Many studies also reveal a positive influence of mindfulness training in dealing with emotional problems (Eifert \& Heffner, 2003).

\section{AIM OF THE STUDY AND RESEARCH HYPOTHESIS}

The purpose of this study is to test two hypotheses. The first concerns the differences between individuals with borderline personality organization and those with personality organization higher than borderline, in terms of both orientation to inner experience (mentalization and mindfulness) and emotional dysregulation, understood as the result of an insufficient orientation towards internal mental states. On the basis of theory, as well as other empirical verification, we assumed that, in the BPO group, the level of mindfulness and mentalization will be significantly lower than in the control group. Furthermore, we expected that the level of emotion dysregulation will be higher in the BPO group. The second hypothesis concerned the mediating role of emotional dysregulation in the relationship between mentalization and $\mathrm{BPO}$, as well as in the relationship between mindfulness and BPO. In line with the assumption that assigns a mainly regulatory role to mentalization, we expected that the significance of the relationship between mentalization and BPO would considerably decrease, or entirely disappear, upon taking into account emotional dysregulation as a mediator. We likewise hypothesized the same for the relationship between mindfulness and BPO.

\section{PARTICIPANTS AND PROCEDURE}

The research presented here is a part of a broader research project focused on borderline personality organization and mentalization (Górska \& Marszał, 2014).

\section{PARTICIPANTS}

The clinical group $(n=30)$ consisted of patients from the Hospital for Mental Diseases in Miecdzyrzecz and Medison Private Health Care in Koszalin. The patients were diagnosed as having BPO on the basis of the results of the screening test (Leichsenring, 1999). The control group $(n=30)$ consisted of individuals from the general population, not undergoing treatment for emotional disorders, and diagnosed as having more mature personality organizations than BPO. To eliminate the influence of age, gender, and education on the differences between the groups, a procedure of matching pairs was used. In each group, there were 17 women and 13 men, aged $M=30.77$ $(S D=9.21$, min. $=18.00, \max .=50.00)$. The levels of education obtained were as follows: $20.00 \%$ had completed primary and vocational school, $23.30 \%$ had completed high school, $26.60 \%$ had begun but not completed third-level education, and $20.00 \%$ had completed third-level education. All the subjects gave their informed consent at each stage of the research procedure.

\section{RESEARCH METHODS}

The experimenters conducting the study were psychologists or clinical psychology students trained in the assessment procedure. All of the subjects were examined 1) using a screening questionnaire, which was the qualification for the clinical or control group; 2) to determine the level of mentalization; 3) to determine the level of mindfulness; 4) and to determine the level of emotional dysregulation. 
The Borderline Personality Inventory (BPI, Leichsenring, 1999; Polish version by Cierpiałkowska, 2001) is a self-report instrument recommended for large-scale screening of BPO, based on Kernberg's structural theory of personality organization, regarding: identity diffusion, primitive defense mechanisms, reality testing, and fear of fusion (see, e.g., Clarkin, Lenzenweger, Yeomans, Levy, \& Kernberg, 2007). The questionnaire consists of 53 questions; each "True" answer scores 1 point and each "False" answer earns 0 points. The overall score is the sum of all points scored in the questionnaire. An individual is diagnosed with BPO when the overall score is greater than 20 points. The most discriminatory items are included in the shorter Cut-20 scale, which provides a cut-off score: Cut- 20 results $\geq 10$ are recommended as the cut-off point for the proper classification of borderline patients. In our research, we used Cut-20 $\geq 10$ for assignment to the clinical group and Cut- $20 \leq 5$ for assignment to the control group. The BPI has good internal consistency, test-retest reliability, and satisfactory rates of sensitivity (.85 to $.89)$ and specificity (.78 to .90$)$. The reliability of the subscales measured by the test-retest method was $r_{t t}=.73-.89$ (Leichsenring, 1999). The reliability coefficient for the Polish version of the BPI reaches $\alpha=.94$ for the whole questionnaire.

The Mental States Task (MST, 2010, 2013; adapted by Kwiecień, 2011) evaluates individual differences in two processes: representation-elaboration and openness-modulation to subjective experience. First, participants were primed with the $3 \mathrm{BM}$ card of the Thematic Apperception Test (Murray, 1971), in order to evoke emotional arousal and regulation strategies. They were then asked to write down a story that came to mind in response to the image. Next, participants responded to 24 items assessing their mental states during the previous task. The MST measures the following six mental states, which reflect the interactions between the activation of mental representations and their modulation: Concrete Thinking: a significant defect in the elaboration of subjective experience, low awareness of one's mental contents; Low Defensive Level: the activation of representational contents makes the subject emotionally overwhelmed, and the mental contents are defended against through immature defenses (e.g., splitting, distortion, acting out); Intermediate Defensive Level: the recognition and elaboration of the representational contents are impeded, and the person's subjective experience is obliterated, or its meaning downplayed, by defenses of denial, minimization, or emotional suppression; Objective-Rational: the subjective experience is treated with an objectifying attitude and distance; High Defensive Level: elaboration on and openness to the true subjective experience is present, but is defended against by more mature defenses and adaptive emotion regulation strategies;
Reflective Thinking: the capacity to recognize and elaborate the full subjective experience, associated with some use of mature defenses and emotion regulation strategies. The score for each subscale reflects the scores for each mental state, with the total MST score being obtained by using an equation that incorporates weights to reproduce the reflective continuum. The MST has good reliability coefficients (.79-.58 for the English version and .82-.62 for the French version) (Lecours \& Bouchard, 2011).

Mindful Attention Awareness Scale (MAAS, Brown \& Ryan, 2003; adapted by Jankowski, 2006). The mindfulness questionnaire concerns this ability in terms of its disposal. Mindfulness is understood as an awareness of emotions, thoughts, feelings, and situations, while directing attention toward them. The MAAS consists of 15 items. The participant answers the questions about the frequency of experiencing the states described (on a 6-point Likert scale where 1 means "almost always" and 6 means "almost never"). The authors of the method assumed that the participant has better access to the experience of mindfulness when the statements describe the contradiction of the state in which it occurs. The overall result is an average calculated on the basis of all the items, ranging from 15 to 80 points. The higher the score on the general scale is, the more the state of mindfulness is observed in the individual. Mindful Attention Awareness Scale has good reliability coefficients that range from .80 to .87 (Brown \& Ryan, 2003; Jankowski, 2006); in our study $\alpha=.88$.

Difficulties of Emotion Regulation Scale (DERS, Gratz \& Roemer, 2004): the scale measures difficulties in emotion regulation, and was used in individuals suffering from anxiety disorder and borderline personality disorder (Gratz \& Gunderson, 2006; Salters-Pedneault, Roemer, Tull, Rucker, \& Mennin, 2006). The scale estimates the level of regulatory deficits in six functions which are considered to be essential components of emotion dysregulation. They contribute to the subscales of DERS: nonacceptance of emotional responses, difficulties engaging in goal-directed behavior, impulse control difficulties, and limited access to emotion, regulation strategies, lack of emotional awareness and lack of emotional clarity (Gratz \& Roemer, 2004). The DERS has good reliability coefficients; $\alpha=.94$.

\section{RESULTS}

The results presented in Table 1 indicate a strong positive correlation between $\mathrm{BPO}$ and emotion dysregulation $(r=.75, p<.001)$. An equally strong, though negative, relationship was observed between BPO and mindfulness $(r=-.74, p<.001)$. The relationship between $\mathrm{BPO}$ and mentalization was revealed in the case of two scales: a Low Defensive Level positively 
Table 1

Correlations between main study variables

\begin{tabular}{|c|c|c|c|c|c|c|c|c|c|c|}
\hline & $\mathrm{BPI}$ & $\begin{array}{c}\text { BPI- } \\
\text { CUT20 }\end{array}$ & DERS & MAAS & $\begin{array}{c}\text { MST- } \\
\text { CT }\end{array}$ & $\begin{array}{l}\text { MST- } \\
\text { LDL }\end{array}$ & $\begin{array}{l}\text { MST- } \\
\text { IDL }\end{array}$ & $\begin{array}{c}\text { MST- } \\
\text { OR }\end{array}$ & $\begin{array}{l}\text { MST- } \\
\text { HDL }\end{array}$ & $\begin{array}{c}\text { MST- } \\
\text { RT }\end{array}$ \\
\hline $\mathrm{BPI}$ & 1.00 & & & & & & & & & \\
\hline BPI-CUT20 & $.959^{* *}$ & & & & & & & & & \\
\hline DERS & $.746^{* *}$ & $.748^{* *}$ & & & & & & & & \\
\hline MAAS & $-.740^{* *}$ & $-.690^{* *}$ & $-.732^{* *}$ & & & & & & & \\
\hline MST-CT & -0.16 & -0.22 & $-.279^{*}$ & 0.12 & & & & & & \\
\hline MST-LDL & $.541^{* *}$ & $.546^{* *}$ & $.604^{* *}$ & $-.534^{* *}$ & $-.385^{* *}$ & & & & & \\
\hline MST-IDL & -0.18 & $-.261^{*}$ & $-.320^{*}$ & 0.18 & $.294^{*}$ & $-.379^{* *}$ & & & & \\
\hline MST-OR & 0.04 & 0.04 & -0.16 & 0.10 & 0.15 & $-.258^{*}$ & -0.22 & & & \\
\hline MST-HDL & -0.10 & -0.12 & -0.22 & 0.03 & 0.14 & 0.06 & 0.05 & 0.04 & & \\
\hline MST-RT & -0.08 & -0.07 & -0.17 & 0.09 & -0.19 & -0.01 & 0.03 & $.286^{*}$ & 0.24 & \\
\hline MST-GS & -0.22 & -0.17 & $-.260^{*}$ & 0.20 & $-.386^{* *}$ & -0.19 & -0.23 & $.276^{*}$ & $.572^{* *}$ & $.660^{* *}$ \\
\hline
\end{tabular}

Note. BPI - Borderline Personality Inventory, DERS - Difficulties of Emotion Regulation Scale, MAAS - Mindful Attention Awareness Scale, MST-CT - Concrete Thinking, MST-LDL - Low Defensive Level, MST-IDL - Intermediate Defensive Level, MST-OR - Objective-Rational, MST-HDL - High Defensive Level, MST-RT - Reflective Thinking, MST-GS - general score. ${ }^{*} p<.05,{ }^{* *} p<.01$

correlated with BPO, while an Intermediate Defensive Level was negatively correlated with BPO. However, this correlation was relatively weak and significant only in the case of the CUT-20 scale. Moreover, a correlation between emotion dysregulation and mindfulness was demonstrated, as was one between emotion dysregulation and the three dimensions of mentalization (Concrete Thinking, Low Defensive Level, Intermediate Defensive Level). The relationship between mindfulness and mentalization was observed only for one style of mentalization: Low Defensive Level (Table 1).

Due to the abnormal distribution of the variables, the Wilcoxon test for independent variables was used to identify intergroup differences. The BPO and the control group differed from each other in terms of emotional dysregulation, mindfulness, and mentalization (see Table 2). Borderline personality organization individuals obtain significantly higher scores on emotional dysregulation scales (Nonacceptance, Goals, Impulse, Strategies, Clarity, but not Awareness). They also demonstrate significantly lower levels of mindfulness. In terms of mentalization, BPO individuals demonstrate significantly higher scores on Low Defensive Level and significantly lower scores on Intermediate Defensive Level. No differences in terms of more mature styles of mentalization were observed.

In order to verify the hypothesis regarding the mediating role of emotional dysregulation on the relationship between mindfulness or mentalization and $\mathrm{BPO}$, an analysis of mediation was conducted, com- plemented with the Goodman test. The analysis was performed in three steps (Baron \& Kenny, 1986), separately for the relationship between mentalization and BPO, and for mindfulness and BPO. In the case of mentalization, only Low Defensive Level was included in the analyses, because it revealed the strongest association with both $\mathrm{BPO}$ and emotion dysregulation. In the first step, a regression analysis was performed, which confirmed that primitive defense mechanisms are a predictor of $\mathrm{BPO}(\beta=.54, p<.001)$. In the second step, a relationship between an independent variable and the mediator (emotion dysregulation) was found $(\beta=.60, p<.001)$, as was one between the mediator and the dependent variable $(\beta=.75, p<.001)$. In the final step, the analysis took into account the independent variable, the mediator, and the dependent variable all together. Hierarchical regression analysis was performed. In the first step, Low Defensive Level was included as a predictor of BPO; in a second step, emotion dysregulation was introduced (see Table 3). The results indicate that a significant amount of the variance in the relationship between Low Defensive Level and BPO is explained by emotion dysregulation. The relationship with Low Defensive Level has ceased to be significant, which shows the complete mediation of this relationship by emotional dysregulation. This result was confirmed using the Goodman test: $Z=4.29, p<.001$ (Figure 1 ).

The same analyses were performed concurrently for mindfulness. In the first step, using regression analysis, it was found that mindfulness is a predictor of BPO $(\beta=-.74, p<.001)$. Next, the relationships 
Table 2

Group differences in emotion dysregulation, mindfulness and mentalization

\begin{tabular}{|c|c|c|c|c|c|}
\hline & Group & $M$ & $S D$ & $Z$ & $p$ \\
\hline \multirow{2}{*}{ DERS } & control & 80.47 & 20.98 & \multirow{2}{*}{-5.44} & \multirow{2}{*}{$<.001$} \\
\hline & BPO & 122.43 & 19.72 & & \\
\hline \multirow{2}{*}{ MAAS } & control & 66.10 & 10.30 & \multirow{2}{*}{-4.39} & \multirow{2}{*}{$<.001$} \\
\hline & BPO & 50.60 & 12.09 & & \\
\hline \multirow{2}{*}{ MST-CT } & control & 14.20 & 5.50 & \multirow{2}{*}{-1.86} & \multirow{2}{*}{.063} \\
\hline & BPO & 11.40 & 5.45 & & \\
\hline \multirow{2}{*}{ MST-LDL } & control & 10.57 & 4.28 & \multirow{2}{*}{-4.16} & \multirow{2}{*}{$<.001$} \\
\hline & BPO & 16.90 & 5.64 & & \\
\hline \multirow{2}{*}{ MST-IDL } & control & 10.03 & 3.75 & \multirow{2}{*}{-2.33} & \multirow{2}{*}{.020} \\
\hline & BPO & 7.83 & 3.01 & & \\
\hline \multirow{2}{*}{ MST-OR } & control & 16.97 & 4.25 & \multirow{2}{*}{-0.65} & \multirow{2}{*}{.514} \\
\hline & BPO & 17.80 & 5.24 & & \\
\hline \multirow{2}{*}{ MST-HDL } & control & 15.90 & 5.69 & \multirow{2}{*}{-0.82} & \multirow{2}{*}{.414} \\
\hline & $\mathrm{BPO}$ & 14.47 & 6.34 & & \\
\hline \multirow{2}{*}{ MST-RT } & control & 16.47 & 5.48 & \multirow{2}{*}{-0.91} & \multirow{2}{*}{.361} \\
\hline & BPO & 15.93 & 2.85 & & \\
\hline \multirow{2}{*}{ MST-GS } & control & 3.69 & 0.30 & \multirow{2}{*}{-1.07} & \multirow{2}{*}{.284} \\
\hline & $\mathrm{BPO}$ & 3.65 & 0.22 & & \\
\hline
\end{tabular}

Note. DERS - Difficulties of Emotion Regulation Scale, MAAS - Mindful Attention Awareness Scale, MST-CT - Concrete Thinking, MST-LDL - Low Defensive Level, MST-IDL Intermediate Defensive Level, MST-OR - Objective-Rational, MST-HDL - High Defensive Level, MST-RT - Reflective Thinking, MST-GS - general score.

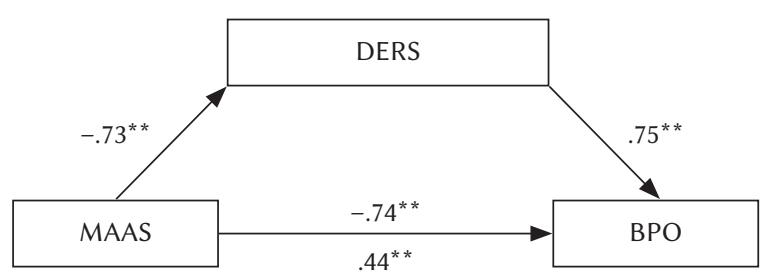

Note. MAAS - Mindful Attention Awareness Scale, DERS Difficulties of Emotion Regulation Scale, BPO - borderline personality organization

${ }^{* *} p<.001$

Figure 2. Emotion dysregulation (DERS) as a mediator of the relation between mindfulness (MAAS) and borderline personality organization (BPO).

between the mediator and mindfulness $(\beta=-.73$, $p<.001)$ and between the mediator and BPO $(\beta=.75$, $p<.001)$ were observed. Lastly, a two-step hierarchical regression was conducted to test for mediation with mindfulness regressed on $\mathrm{BPO}$; this was
Table 3

Summary of hierarchical regression analysis for the relationships between mentalization (low defensive level), emotion dysregulation and borderline personality organization (dependent variable) $(N=60)$

\begin{tabular}{lllll}
\hline$B$ & SE $B$ & $\beta$ & $\begin{array}{c}R^{2} \\
\left(R^{2} \text { change }\right)\end{array}$ & $p$
\end{tabular}

\begin{tabular}{|c|c|c|c|c|c|}
\hline Step 1 & & & & & \\
\hline MST-LDL & 1.02 & .20 & $.54^{* *}$ & .29 & $<.001$ \\
\hline Step 2 & & & & & \\
\hline MST-LDL & .27 & .20 & .14 & $.55(.28)$ & $<.001$ \\
\hline DERS & .25 & .04 & $.66^{* *}$ & & \\
\hline \multicolumn{6}{|c|}{$\begin{array}{l}\text { Note. MST-LDL - Mental State Task - Low Defensive Level, } \\
\text { DERS - Difficulties of Emotion Regulation Scale } \\
{ }^{* *} p<.001\end{array}$} \\
\hline & & \multicolumn{2}{|c|}{ DERS } & & \\
\hline \multirow[t]{2}{*}{ MST-LDL } & & \multicolumn{2}{|c|}{$.54^{* *}$} & \multicolumn{2}{|c|}{ BPO } \\
\hline & & & & \\
\hline
\end{tabular}

Note. MST-LDL - Mental State Task - Low Defensive Level, DERS - Difficulties of Emotion Regulation Scale, BPO borderline personality organization ${ }^{* *} p<.001$

Figure 1. Emotion dysregulation (DERS) as a mediator of the relation between Low Defensive Level (MST-LDL) and borderline personality organization (BPO).

Table 4

Summary of hierarchical regression analysis for the relationships between mindfulness, emotion dysregulation and borderline personality organization (dependent variable) $(N=60)$

\begin{tabular}{cccccc}
\hline & $B$ & SE B & $\beta$ & $\begin{array}{c}R^{2} \\
\left(R^{2} \text { change }\right)\end{array}$ & $p$ \\
\hline Step 1 & & & & & \\
MAAS & -.60 & .07 & -.74 & .55 & $<.001$ \\
Step 2 & & & & & \\
MAAS & -.34 & .10 & -.42 & $.63(.09)$ & $<.001$ \\
DERS & .17 & & .44 & & \\
\hline
\end{tabular}

MAAS - Mindful Attention Awareness Scale,

DERS - Difficulties of Emotion Regulation Scale

followed by adding emotion dysregulation to the regression (Table 4). With this addition, the relationship between mindfulness and BPO was less significant (partial mediation). To test the significance of the decrease seen in the predictor-dependent relation 
when the mediator was entered into the model, the Goodman test was conducted: $Z=-6.21, p<.001$ (Figure 2).

\section{DISCUSSION AND CONCLUSIONS}

The aim of this study was to broaden the understanding of the mechanism behind the genesis and maintenance of BPO on the basis of the variables presented in the literature as predictors of borderline pathology: mentalization, mindfulness, and emotion regulation. It was expected that $\mathrm{BPO}$ and the personality organizations higher than $\mathrm{BPO}$ would be differentiated with respect to these variables. Moreover, it was assumed that the relationships between these variables would reflect the hierarchical model in which the orientation towards internal states (here conceptualized as mentalization and mindfulness) accounts for emotion regulation. Two hypotheses were thus put forward. The basic hypothesis assumed that people in the borderline groups and individuals in the control group would vary in terms of these three variables. As expected, it was determined that the BPO group presented lower scores in the level of mindfulness and ability to regulate emotions. In terms of mentalization, differences were observed in the two mental states. For the BPO group, the process of elaboration and modulation of emotional experience was found to be more overwhelming than for the control group, being accompanied by defenses against the experience based on externalization and dissociation. At the same time, this group to a lesser extent impeded their recognition and elaboration of the emotional experience through mechanisms based on denial and suppression. These results correspond to the results obtained previously by other authors (Preißler, Dziobek, Ritter, Heekeren, \& Roepke, 2010; Fisher-Kern et al., 2010; Wuppermann et al., 2008, 2009), including in terms of some of the dimensions of mentalization which are relevant to BPO (Sharp et al., 2011; Marszał, 2015).

Subsequently, the hypothesis of the mediation by emotional dysregulation of the relationship between mentalization and BPO (and between mindfulness and $\mathrm{BPO}$ ) was tested. This hypothesis was based on the assumption that the meaning of states of mind oriented towards emotional experience for $\mathrm{BPO}$ is primarily determined by their regulatory functions regarding emotions. In other words, it is not mentalization and mindfulness per se that are relevant to $\mathrm{BPO}$, but their influence on the formation of emotional pathology in BPO. This hypothesis has been confirmed for one of the dimensions of mentalization - the primitive defense mechanisms. The results suggest the following mechanism: when the content of representation is threatening, the activation of these representations becomes excessively overwhelming.
Recognition, awareness, and reflection on them are too painful and devastating. This causes an affective arousal that cannot be neutralized or processed in an appropriate manner (Beaulieu-Pelletier, Bouchard, \& Philippe, 2013; Lecours \& Bouchard, 2011). The result is emotional dysregulation that manifests in two possible ways. On one hand, these raw, unprocessed, and often unconscious negative affects are the display of emotional dysregulation itself. On the other hand, inadequate regulation strategies are employed - for example, primitive defense mechanisms based on externalization and splitting, which results in emotional symptoms. The mechanism observed in this study also corresponds to the process of switching between controlled and automatic mentalization described by Fonagy (Fonagy \& Luyten, 2009; Fonagy et al., 2013). It seems that the inability to represent and elaborate activated subjective experience goes hand in hand with switching to automatic mode, which results in emotional dysregulation.

Studies of the mediating function of emotional dysregulation in the relation between mentalization and BPD have also been conducted by Sharp \& Fonagy (2008), who indicated that the relation between hypermentalizing and BPD traits was partially mediated by difficulties in emotion regulation, which leads them to conclude that mentalizing and emotion dysregulation represent separate though interacting difficulties in individuals with a vulnerability to BPD. The total mediation (referred to primitive defenses) described in our study would suggest that the role of mentalization in BPO manifests itself mainly in its impact on the difficulties in emotion regulation. Thus, those variables which constitute BPO predictors reflect levels in the hierarchical model on which difficulties in emotion regulation are determined and influenced by the ability of a higher level - the orientation to subjective experiences.

It should also be explicitly pointed out that the relationship of only one mentalization dimension (Low Defensive Level) with BPO was mediated by emotional dysregulation. Moreover, the use of primitive defense mechanisms in response to threatening subjective experiences was significantly more frequent in the BPO group and was also an important predictor of BPO. However, the effect of the impact of this mentalization style on BPO disappeared when emotion dysregulation was introduced to the model as a mediating variable (total mediation). From the other mentalization dimensions, only Intermediate Defensive Level differentiated the clinical and control groups (see Górska \& Marszał, 2014), yet it did not prove to be an important predictor of BPO. It follows that mentalization is a complex construct of many different dimensions, which may be distinct from each other and serve different functions (see Semerari et al., 2007). 
Simultaneously with the verification of the regulatory function of mentalization, the hypothesis of the role of mindfulness in emotional dysregulation in BPO was tested. It was discovered that the relationship between mindfulness and BPO is partially mediated by emotional dysregulation. It seems that mindfulness only partly consists of a regulatory function, and that its nature is largely cognitive. The literature suggests that mindfulness affects individual functioning in two ways: by indirectly influencing an increased ability to self-regulate while directly enhancing a lack of prejudices, accepting the experience of subjective experience (Fossati et al., 2012). Our results underline both indirect and direct relationships between mindfulness and BPO. On the one hand, low mindfulness determines a reduced ability to regulate emotions, which leads to BPO symptom enhancement, thus reflecting the regulative function of mindfulness. On the other hand, this decentered attitude towards the inner experience is directly related to BPO.

There remains the question of the relationships between mentalization and mindfulness in both developmental and structural perspectives. Some approaches assume that mindfulness is the essential starting place from which genuine mentalization can arise (Fossati et al., 2012). However, in the frame of the object relation theory, there arises a question: does mindfulness refer to the primitive, unaware emotions observed in BPO? It is worth considering a different viewpoint: that if mindfulness operates on consciousness and demands some basic level of recognition of emotional states, then for that reason it is connected with later developmental stages than the early forms of mentalization. Kernberg (2011) compares mindfulness with containment (Bion, 1962), interpreting it as unconscious identification with a loving maternal introject. This kind of mature mindfulness may be a feature of an integrated personality, in which splitting is replaced by denial: the unconscious identification with a good object, which neutralizes the negative affect by containing the results in the appropriate emotion regulation. However, in borderline personality organization, which is dominated by splitting, the image of the good object is unstable and difficult to evoke, so there is an impaired ability to contain the aggressive and threatening feelings. This is probably the reason for the lack of mature forms of mindfulness in BPO. Kernberg (2011) suggests that focusing on the acceptance of all the "self at the moment" may take a distorted form, perhaps leading to the promotion of self-idealization, reinforcing omnipotent narcissistic object relations and the illusion that everything that is valuable emanates in the experience of the self in the moment. The primary goal of mindfulness - the acceptance of experienced emotions - is then distorted. It is not the acceptance associated with maternal feelings of understanding and forgiveness, which leads to aggression neutralization and to an adequate assessment of one's own self, but an acceptance based on idealization, defensive against the devalued part of the self-image. This distorted kind of mindfulness, as occur in dissociated, not integrated personalities, cannot lead to emotion regulation. The relationship between mindfulness and the level of integration of personality and emotional dysregulation thus seems to be at least tangled: mindfulness based on idealization probably enhances dysregulation in BPO, but in personality organization higher than BPO, it actually has a regulatory function. The nature of such differentiation may become a further research direction.

The present study has certain limitations. First of all, there is no common opinion among researchers on what mentalization and mindfulness actually are, or on how they should be operationalized and tested (Christopher, Charoensuk, Gilbert, Neary, \& Pearce, 2009; Van Dam, Earleywine, \& Borders, 2010; Choi-Kain \& Gunderson, 2008). The generalization of the results should therefore be limited by our way of understanding both capabilities. This particularly refers to using only the individual perspective in understanding mentalization, while emotion regulation and mentalization are, above all, processes involving the interpersonal context, beside the self-reflexive context (Fonagy \& Luyten, 2009). Another limitation is the small sample size and the large intragroup differences in terms of age and education. The impact of these variables has been minimized through the use of the matching pairs procedure. Careful generalization of the results - especially connected with the meditating role of emotion dysregulation - should thus allow the replication of this study in larger and more homogeneous populations.

Financed by the research grant of Institute of Psychology, Adam Mickiewicz University in Poznan.

\section{REFERENCES}

Andersen, R., Timmerby, N., \& Simonsen, E. (2012). Affect regulation and psychopathology in women with borderline personality disorder. Danish Medical Journal, 59, A4521.

Baer, R. A., Smith, G. T., \& Allen, K. B. (2004). Assessment of mindfulness by self-report: the Kentucky inventory of mindfulness skills. Assessment, 11, 191-206.

Baron-Cohen, S., Wheelwright, S., Hill, J., Raste, Y., \& Plumb, I. (2001). The "Reading the Mind in the Eyes" Test revised version: a study with normal adults, and adults with Asperger syndrome or high-functioning autism. Journal of Child Psychology and Psychiatry, and Allied Disciplines, 42, 241251. 
Baron, R. M., \& Kenny, D. A. (1986). The moderator-mediator variable distinction in social psychological research: Conceptual, strategic and statistical considerations. Journal of Personality and Social Psychology, 51, 1173-1182.

Bateman, A., \& Fonagy, P. (2013). Terapia oparta na mentalizacji a zaburzenie osobowości borderline [Mentalization Based Treatment and Borderline Personality Disorder]. In: J. F. Clarkin, P. Fonagy, \& G. Gabbard (eds.), Psychoterapia psychodynamiczna zaburzeń osobowości [Psychodynamic Psychotherapy for Personality Disorders] (pp. 233-259). Kraków: Wydawnictwo Uniwersytetu Jagiellońskiego.

Beaulieu-Pelletier, G., Bouchard, M.-A., \& Philippe, F. L. (2013). Mental States Task (MST): development, validation, and correlates of a self-report measure of mentalization. Journal of Clinical Psychology, 69, 671-695.

Beblo, T., Pastuszak, A., Griepenstroh, J., Fernando, S., Driessen, M., Schütz, A., Rentzsch, K., \& Schlosser, N. (2010). Self-reported emotional dysregulation but no impairment of emotional intelligence in borderline personality disorder: an explorative study. The Journal of Nervous and Mental Disease, 198, 385-388.

Bion, W. R. (1962). The psycho-analytic study of thinking. International Journal of Psycho-Analysis, 43, 306-310.

Bishop, S. R., Lau, M., Shapiro, S., Carlson, L., Anderson, N. D., Carmody, J., Segal, Z. V., Abbey, S., Speca, M., Velting, D., \& Devins, G. (2004). Mindfulness: A Proposed Operational Definition. Clinical Psychology: Science and Practice, 11, 230-241.

Borders, A., Earleywine, M., \& Jajodia, A. (2010). Could mindfulness decrease anger, hostility, and aggression by decreasing rumination? Aggressive Behavior, 36, 28-44. DOI: 10.1002/ab.20327

Brown, K. W., \& Ryan, R. M. (2003). The benefits of being present: mindfulness and its role in psychological well-being. Journal of Personality and Social Psychology, 84, 822-848.

Caligor, E., \& Clarkin, J. (2013). Model osobowości i patologii osobowości oparty na teorii relacji z obiektem [An Object Relations Model of Personality and Personality Pathology]. In J. F. Clarkin, P. Fonagy, \& G. O. Gabbard (eds.), Psychoterapia psychodynamiczna zaburzeń osobowości [Psychodynamic Psychotherapy for Personality Disorders] (pp. 23-61). Kraków: Wydawnictwo Uniwersytetu Jagiellońskiego.

Carlson, L. E., \& Brown, K. W. (2005). Validation of the Mindful Attention Awareness Scale in a cancer population. Journal of Psychosomatic Research, 58, 29-33.

Choi-Kain, L., \& Gunderson, J. (2008). Mentalization: Ontogeny, Assessment, and Application in the Treatment of Borderline Personality Disorder. American Journal of Psychiatry, 165, 1127-1135.

Christopher, M. S., Charoensuk, S., Gilbert, B. D., Neary, T. J., \& Pearce, K. L. (2009). Mindfulness in Thailand and the United States: a case of apples versus oranges? Journal of Clinical Psychology, 65, 590-612.

Cierpiałkowska, L. (2001). Adaptacja Kwestionariusza Zaburzenia Osobowości Borderline F. Leichsenringa [Adaptation of F. Leichsenring's Borderline Personality Inventory. Unpublished manuscript].

Clarkin, J. F., Lenzenweger, M. F., Yeomans, F., Levy, K. N., \& Kernberg, O. F. (2007). An object relations model of borderline pathology. Journal of Personality Disorders, 21, 474-499.

Dimaggio, G., Nicolo, G., Fiore, D., Centenero, E., Semerari, A., Carcione, A., \& Pedone, R. (2008). States of minds in narcissistic personality disorder: three psychotherapies analyzed using the grid of problematic states. Psychotherapy $R e-$ search: Journal of the Society for Psychotherapy Research, 18, 466-480.

Ebner-Priemer, U. W., Welch, S. S., Grossman, P., Reisch, T., Linehan, M. M., \& Bohus, M. (2007). Psychophysiological ambulatory assessment of affective dysregulation in borderline personality disorder. Psychiatry Research, 150, 265-275.

Eifert, G. H., \& Heffner, M. (2003). The effects of acceptance versus control contexts on avoidance of panic-related symptoms. Journal of Behavior Therapy and Experimental Psychiatry, 34, 293-312.

Fertuck, E. A., Jekal, A., Song, I., Wyman, B., Morris, M. C., Wilson, S. T., Brodsky, B. S., \& Stanley, B. (2009). Enhanced "Reading the Mind in the Eyes" in borderline personality disorder compared to healthy controls. Psychological Medicine, 39, 1979-1988.

Fischer-Kern, M., Buchheim, A., Hörz, S., Schuster, P., Doering, S., Kapusta, N. D., Taubner, S., Tmej, A., Rentrop, M., Buchheim, P., \& Fonagy, P. (2010). The relationship between personality organization, reflective functioning, and psychiatric classification in borderline personality disorder. Psychoanalytic Psychology, 27, 395-409.

Fonagy, P. (1999). Attachment, the development of the self, and its pathology in personality disorders. In: J. Derksen, C. Maffei, H. Groen, J. Derksen, C. Maffei, \& H. Groen (eds.), Treatment of personality disorders (pp. 53-68). Dordrecht, Netherlands: Kluwer Academic Publishers.

Fonagy, P., \& Luyten, P. (2009). A developmental, mentalization-based approach to the understanding and treatment of borderline personality disorder. Development and Psychopathology, 21, 1355-1381.

Fonagy, P., Luyten, P., Bateman, A., Gergely, G., Strathearn, L., Target, M., \& Allison, E. (2013). Przywiązanie a patologia osobowości [Attachment an Personality Pathology]. In: J. F. Clarkin, P. Fonagy, 
\& G. O. Gabbard (eds.), Psychoterapia psychodynamiczna zaburzeń osobowości [Psychodynamic Psychotherapy for Personality Disorders] (pp. 61119). Kraków: Wydawnictwo Uniwersytetu Jagiellońskiego.

Fossati, A., Vigorelli Porro, F., Maffei, C., \& Borroni, S. (2012). Are the DSM-IV Personality Disorders Related to Mindfulness? An Italian Study on Clinical Participants. Journal of Clinical Psychology, 68, 672-683.

Górska, D. (2013). Dysregulacja emocjonalna i poznawcze aspekty teorii umysłu a dojrzałość mechanizmów obronnych jako wskaźnik poziomu organizacji osobowości [Exploring the relationship between emotion dysregulation, theory of mind and defense mechanisms maturity as an indicator of level of personality organization]. Czasopismo Psychologiczne, 19, 57-66.

Górska, D., \& Marszał, M. (2014). Mentalization and theory of mind in borderline personality organization: exploring the differences between affective and cognitive aspects of social cognition in emotional pathology. Psychiatria Polska, 48, 503-513.

Gratz, K. L., \& Gunderson, J. G. (2006). Preliminary Data on Acceptance-Based Emotion Regulation Group Intervention for Deliberate Self-Harm Among Women with Borderline Personality Disorder. Behavior Therapy, 37, 25-35.

Gratz, K. L., \& Roemer, L. (2004). Multidimensional Assessment of Emotion Regulation and Dysregulation: Development, Factor Structure, and Initial Validation of the Difficulties in Emotion Regulation Scale. Journal of Psychopathology and Behavioral Assessment, 26, 41-54.

Groth, J. (2005). Natura psychozy według Wilfreda R. Biona [The nature of psychosis according to Wilfred R. Bion]. In: L. Cierpiałkowska, \& J. Gościniak (eds.), Wspótczesna psychoanaliza [Contemporary Psychoanalysis] (pp. 63-80). Poznan: Wydawnictwo Naukowe UAM.

Guttman, H., \& Laporte, L. (2002). Alexithymia, empathy, and psychological symptoms in a family context. Comprehensive Psychiatry, 43, 448-455.

Hall, J. A. (1992). Psychological-mindedness: a conceptual model. American Journal of Psychotherapy, 46, 131-140.

Hayes, S. C., Strosahl, K. D., \& Wilson, K. G. (1999). Acceptance and commitment therapy: an experiential approach to behavior change. New York: Guilford Press.

Hofmann, S. G., Sawyer, A. T., Witt, A. A., \& Oh, D. (2010). The effect of mindfulness-based therapy on anxiety and depression: a meta-analytic review. Journal of Consulting and Clinical Psychology, 78, 169-183.

Jankowski, T. (2006). Struktura koncepcji siebie oraz procesy przetwarzania informacji o sobie u osób o różnym stopniu uważności. Nieopublikowana rozprawa doktorska [The Structure of Self-Concept and Information Processing in Individuals with Different Levels of Mindfulness. Unpublished doctoral thesis].

Kabat-Zinn, J. (1990). Full Catastrophe Living: Using the Wisdom of Your Body and Mind to Face Stress, Pain, and Illness. New York: Delta Trade Paperbacks.

Kernberg, O. (1967). Borderline Personality Organization. Journal of the American Psychoanalytic Association, 15, 641-685.

Kernberg, O. F. (2004). Borderline Personality Disorder and Borderline Personality Organization: Psychopathology and Psychotherapy. In: J. J. Magnavita (ed.), Handbook of Personality Disorders (pp. 92-119). Hoboken, NJ US: John Wiley \& Sons Inc.

Kernberg, O. F., Diamond, D., Yeomans, F. E., Clarkin, J. F., \& Levy, K. N. (2008). Mentalization and attachment in borderline patients in transference focused psychotherapy. In: E. L. Jurist, A. Slade, \& S. Bergner (eds.), Mind to mind: Infant research, neuroscience, and psychoanalysis (pp. 167-201). New York, NY, US: Other Press.

Kernberg, O. (2011). Mentalization, Mindfulness, Insight, Empathy, and Interpretation. In: O. F. Kernberg (ed.), The Inseparable Nature of Love and Aggression. Clinical and Theoretical Perspectives (pp. 57-79). Washington, DC London, England: American Psychiatric Publishing.

Klein, M. (1996). Notes on Some Schizoid Mechanisms. The Journal of Psychotherapy Practice and Research, 5, 160-179.

Kwiecień, A. (2011). Aktywowanie wewnętrznych reprezentacji przywiązania a mentalizacja u osób o strukturze osobowości borderline. Niepublikowana praca magisterska [Mentalization under activating internal attachment representation's in borderline personality organization].

Leahy, R. L., Tirch, D., \& Napolitano, L. A. (2011). Emotion regulation in psychotherapy. New York: Guilford Press.

Lecours, S. (1995). Manuel de cotation de la Grille de l'E'laboration Verbale des Affects (GE'VA) [Unpublished manuscript].

Lecours, S., \& Bouchard, M.-A. (2011). Verbal elaboration of distinct affect categories and BPD symptoms. Psychology and Psychotherapy, 84, 26-41; discussion 98-110.

Leichsenring, F. (1999). Development and first results of the Borderline Personality Inventory: a self-report instrument for assessing borderline personality organization. Journal of Personality Assessment, 73, 45-63.

Linehan, M. M. (1993). Cognitive-behavioral Treatment of Borderline Personality Disorder. New York: Guilford Press. 
Linehan, M. M., Bohus, M., \& Lynch, T. R. (2007). Dialectical behavior therapy for pervasive emotion dysregulation: Theorethical and practical underpinnings. In: J. J. Gross (ed.), Handbook of emotion regulation (pp. 581-605). New York: Guilford Press.

Marszał, M. (2015). Mentalizacja w kontekście przywiązania. Zdolność do rozumienia siebie i innych $u$ osób z osobowościa borderline [Mentalization in the Attachment Context. The Ability to Understand Self and Others in Borderline Individuals]. Warsaw: Difin.

Meins, E., Fernyhough, C., Fradley, E., \& Tuckey, M. (2001). Rethinking maternal sensitivity: mothers' comments on infants' mental processes predict security of attachment at 12 months. Journal of Child Psychology and Psychiatry, and Allied Disciplines, 42, 637-648.

Moriguchi, Y., Ohnishi, T., Lane, R. D., Maeda, M., Mori, T., Nemoto, K., Matsuda, K., \& Komaki, G. (2006). Impaired self-awareness and theory of mind: an fMRI study of mentalizing in alexithymia. Neurolmage, 32, 1472-1482.

Murray, H. A. (1971). Thematic Apperception Test: Manual. Cambridge, MA: Harvard University Press.

O’Connor, T. G., \& Hirsch, N. (1999). Intra-Individual Differences and Relationship-Specificity of Mentalising in Early Adolescence. Social Development, 8, 256-274.

Preißler, S., Dziobek, I., Ritter, K., Heekeren, H. R., \& Roepke, S. (2010). Social Cognition in Borderline Personality Disorder: Evidence for Disturbed Recognition of the Emotions, Thoughts, and Intentions of others. Frontiers in Behavioral Neuroscience, 4, 182.

Saavedra, M. C., Chapman, K. E., \& Rogge, R. D. (2010). Clarifying links between attachment and relationship quality: hostile conflict and mindfulness as moderators. Journal of Family Psychology, 24, 380-390.

Salters-Pedneault, K., Roemer, L., Tull, M.T., Rucker, L., \& Mennin, D. S. (2006). Evidence of broad deficits in emotion regulation associated with chronic worry and generalized anxiety disorder. Cognitive Therapy and Research, 30, 469-480.

Sarkar, J., \& Adshead, G. (2006). Personality disorders as disorganisation of attachment and affect regulation. Advances in Psychiatric Treatment, 12, 297-305.

Saulsman, L. M., \& Page, A. C. (2004). The five-factor model and personality disorder empirical literature: A meta-analytic review. Clinical Psychology Review, 23, 1055-1085.

Scott, L. N., Levy, K. N., Adams, R. B., Jr, \& Stevenson, M. T. (2011). Mental state decoding abilities in young adults with borderline personality disorder traits. Personality Disorders, 2, 98-112.
Semerari, A., Carcione, A., Dimaggio, G., Nicolò, G., \& Procacci, M. (2007). Understanding minds: Different functions and different disorders? The contribution of psychotherapy research. Psychotherapy Research, 17, 106-119.

Shapiro, S. L., Carlson, L. E., Astin, J. A., \& Freedman, B. (2006). Mechanisms of mindfulness. Journal of Clinical Psychology, 62, 373-386.

Sharp, C., \& Fonagy, P. (2008). The Parent's Capacity to Treat the Child as a Psychological Agent: Constructs, Measures and Implications for Developmental Psychopathology. Social Development, 17, 737-754.

Sharp, C., Pane, H., Ha, C., Venta, A., Patel, A. B., Sturek, J., \& Fonagy, P. (2011). Theory of mind and emotion regulation difficulties in adolescents with borderline traits. Journal of the American Academy of Child and Adolescent Psychiatry, 50, 563-573.e1.

Sinclair, H., \& Feigenbaum, J. (2012). Trait Emotional Intelligence and Borderline Personality Disorder. Personality And Individual Differences, 52, 674-679.

Van Dam, N. T., Earleywine, M., \& Borders, A. (2010). Measuring mindfulness? An Item Response Theory analysis of the Mindful Attention Awareness Scale. Personality and Individual Differences, 49, 805-810.

Vermote, R., Fonagy, P., Vertommen, H., Verhaest, Y., Stroobants, R., Vandeneede, B., Corveleyn, J., Lowyck, B., Luyten, P., \& Peuskens, J. (2009). Outcome and outcome trajectories of personality disordered patients during and after a psychoanalytic hospitalization-based treatment. Journal of Personality Disorders, 23, 294-307.

Walsh, J. J., Balint, M. G., Smolira, D. R., Fredericksen, L. K., \& Madsen, S. (2009). Predicting individual differences in mindfulness: The role of trait anxiety, attachment anxiety and attentional control. Personality and Individual Differences, 46, 94-99.

Wupperman, P., Fickling, M., Klemanski, D. H., Berking, M., \& Whitman, J. B. (2013). Borderline personality features and harmful dysregulated behavior: the mediational effect of mindfulness. Journal of Clinical Psychology, 69, 903-911.

Wupperman, P., Neumann, C. S., \& Axelrod, S. R. (2008). Do deficits in mindfulness underlie borderline personality features and core difficulties? Journal of Personality Disorders, 22, 466-482.

Wupperman, P., Neumann, C. S., Whitman, J. B., \& Axelrod, S. R. (2009). The role of mindfulness in borderline personality disorder features. The Journal of Nervous and Mental Disease, 197, 766-771. 